\title{
Circuit
}

Musiques contemporaines

\section{Introduction sous le signe de la guitare électrique}

\section{Jonathan Goldman}

Volume 24, numéro 3, 2014

Pactes faustiens : l'hybridation des genres musicaux après Romitelli

URI : https://id.erudit.org/iderudit/1027606ar

DOI : https://doi.org/10.7202/1027606ar

Aller au sommaire du numéro

Éditeur(s)

Les Presses de l’Université de Montréal

ISSN

1183-1693 (imprimé)

1488-9692 (numérique)

Découvrir la revue

Citer ce document

Goldman, J. (2014). Introduction sous le signe de la guitare électrique. Circuit, 24(3), 5-8. https://doi.org/10.7202/1027606ar d'utilisation que vous pouvez consulter en ligne.

https://apropos.erudit.org/fr/usagers/politique-dutilisation/ 


\section{Introduction sous le signe de la guitare électrique}

Jonathan Goldman

Dans l'introduction à leur ouvrage phare Western Music and its Others, Georgina Born et David Hesmondhalgh affirment sans détour que «mass culture is modernism's other in music as in the other arts ${ }^{1}$. En effet, les adeptes du modernisme musical des temps «héroïques» du sérialisme de l'après-guerre tâchaient, dans leur discours comme dans leur musique, à construire un «cordon sanitaire ${ }^{2}$ » qui les isolait aussi bien de la culture de masse que des forces potentiellement corruptrices de la politique. Mais une nouvelle génération de créateurs, nés autour de 1960, fait preuve d'un rapport tout à fait différent avec la culture populaire. Chez elle, la culture populaire, incarnée par le rock, la télévision ou le cinéma, fait partie des repères culturels instinctifs qui nourrissent leur production, même lorsque celle-ci ne doit rien à elle sur le plan proprement stylistique.

Chez un Fausto Romitelli (1963-2004), compositeur franco-italien disparu trop tôt il y a de cela déjà dix ans, à l'âge de 41 ans, la culture populaire (le rock ou la bande dessinée) est un horizon inébranlable à partir duquel il construit son univers inouii. Comme la plupart des auteurs de ce numéro l'affirment, le rock ne sert pas tant de modèle sonore à sa musique (à un élément près, la partie la plus visible de l'influence rock chez Romitelli étant l'emploi de la guitare électrique dans plusieurs œuvres-clés), mais plutôt de modèle éthique - un flashback émouvant vers l'époque où le rock était synonyme de contre-culture et s'avérait être le médium idéal pour exprimer les cris de cœur et de rage propres à la jeunesse engagée et réveillée de toutes les ères. En cela, l'attitude de Romitelli nous rappelle, malgré toutes les différences, celle d'un autre révolté insolite: Frank Zappa. Par conséquent, ce numéro constitue en quelque sorte le pendant de celui que nous avons consacré au guitariste américain en $2004^{3}$.

\author{
1. Georgina Born et David \\ Hesmondhalgh (2000), Western \\ Music and its Others: Difference, \\ Representation, and Appropriation in \\ Music, Berkeley, University of California \\ Press, p. 16. \\ 2. L'expression - en français dans le \\ texte - a été employée par Richard \\ Taruskin (1995) dans "A Myth of the \\ Twentieth Century: The Rite of Spring, \\ the Tradition of the New, and "The \\ Music Itself" ", Modernism/Modernity, \\ vol. $2, n^{\circ} 1$, p. 6.
}

3. Réjean Beaucage (rédacteur invité) (2004), Frank Zappa: 10 ans après, dossier thématique de Circuit, musiques contemporaines, vol. $14, \mathrm{n}^{\circ} 3$. 
4. Sandeep Bhagwati (1999), "Oper ist Subkultur", in Idem, Komponieren im 21. Jahrhundert: Texte 1993-99, Graz, Institut fur Elektronische Musik (IEM) an der Universität für Musik und darstellende Kunst in Graz, p. 26-34.
Certes, le potentiel «contre-culturel» de la musique de création ne fut que peu exploité à l'heure où les adeptes du «high modernism» sériel ou spectral revendiquaient une place au cœur même de la tradition musicale occidentale, disons, pour caricaturer, comme suite logique des œuvres de Mozart, Brahms, Debussy et les autres. Or, dès lors qu'on ne considère plus la musique contemporaine comme occupant le centre de la tradition, mais plutôt en tant que domaine périphérique sinon «ex-centrique» par rapport à celle-ci, il devient possible de confronter l'expérience des acteurs de la musique contemporaine à celle des adhérents à d'autres sous-cultures («subcultures») comme les «goths», «punks », «mods» ou «hippies». C'est justement le pari de Martin Iddon, qui propose ici une ethnographie du milieu de la musique contemporaine - en fixant son attention sur ses codes de comportement, ses lieux de pèlerinage, et ses modes de construction d'identité, dans le but d'évaluer la part sous-culturelle de "notre » monde, c'est-à-dire celle de la musique contemporaine stricto sensu. C'est par ailleurs une réflexion à laquelle le compositeur Sandeep Bhagwati s'est déjà livré à propos de l'opéra au moment de la création de son ouvre scénique Ramanujan par l'Opéra de Darmstadt en $1998^{4}$. Contre-culturel et même sous-culturel, le rock l'était autour de 1968, et Romitelli véhicule cet esprit dans sa musique. Cet aspect de sa production a certainement contribué à l'attrait de celle-ci auprès d'une génération plus jeune de compositeurs nés après 1970, comme l'explique Pierre Rigaudière dans un article consacré à trois créateurs français (Franck Bedrossian, Raphaël Cendo et Yann Robin) qui se réclament de près ou de loin du courant (mouvement? école? technique?) dit «saturationniste».

Pour revenir à la musique de Romitelli, signalons que le Québec n’est pas étranger à son récit de vie: rappelons que c'était Lorraine Vaillancourt et son Nouvel Ensemble Moderne (NEM), en compagnie de la soprano québécoise Marie-Annick Béliveau, qui ont créé Lost (textes de Jim Morrison) lors du stage Voix nouvelles de Royaumont (France) en 1997, tel que l'atteste le programme reproduit dans ces pages en guise de Document. Plus récemment, le jeune et dynamique ensemble montréalais La Machine a assuré la création montréalaise du triptyque Professor Bad Trip (1998-2000) en 2012. Plusieurs compositeurs et musiciens du territoire canadien, que ce soit Jean-François Laporte, Wolf Edwards, Yannick Plamondon ou Julien Bilodeau, affichent des similitudes avec l'esthétique de ce compositeur à la fois rigoureux, revendicateur et irrévérent. La démarche d'un compositeur/guitariste comme Sylvain Pohu nous a paru en phase avec celle de Romitelli et de sa progéniture artistique. Notre Exclusivité web propose ainsi une vidéo documentant 
la création de Feedback (2014), œuvre pour guitare électrique et dispositif électronique inspirée du roman pugnace Fight Club de Charles Palahniuk. De plus, dans le cadre de l'Enquête de ce numéro, Maxime McKinley explore l'influence du compositeur italien sur les musiciens du Québec à travers les témoignages de Marie-Annick Béliveau, Julien Bilodeau, Jimmie LeBlanc, Jean-François Laporte, Pohu et Lorraine Vaillancourt. Chez certains, le rapport d'influence est explicite et assumé. C'est le cas de Bilodeau, qui a étudié avec le compositeur à Royaumont et a composé une œuvre à sa mémoire (KroniKs_04, pour l'ensemble L'Itinéraire), ou de LeBlanc, qui a réalisé Perdre pied (2005-2006), un «opéra-performance » dans l'esprit du «vidéo-opéra» de Romitelli An Index of Metals (2003), œuvre ultime du compositeur italien. Chez d'autres, l'influence reste plus difficile à mesurer, mais n'est nullement moins présente.

Si le NEM a très tôt reconnu l'originalité du compositeur italien, c'est à l'ensemble belge Ictus que l'on doit bon nombre des œuvres de maturité de Romitelli. Quatre opus, parmi lesquels Professor Bad Trip: Lesson III (2000) et An Index of Metals (2003), sont ainsi nés d'une collaboration fructueuse entre le compositeur et cet ensemble, et plus particulièrement avec son directeur artistique Jean-Luc Plouvier, qui propose ici un fin examen de l'esthétique de Romitelli, ainsi qu'un témoignage sur ses collaborations déterminantes - dont une trace durable est heureusement conservée sur le disque que l'ensemble Ictus a réalisé en $2004^{5}$. Pour sa part, Martin Kaltenecker propose un texte pénétrant qui replace l'œuvre de Romitelli dans un contexte historico-esthétique caractérisé par un "paradigme prédominant du son", marqué "par les idées de continuité, de fusion sonore, de corporéité et d'écoute efficace». Soulignons enfin que les illustrations qui ornent ce numéro habitent l'univers de la bande dessinée et sont l'œuvre du regretté dessinateur Gianluca Lerici (1963-2006), le Professor Bad Trip qui inspira l'œuvre éponyme de Fausto Romitelli.

Dans la section des Actualités, Cléo Palacio-Quintin propose une rétrospective des créations 2013-2014 de la série de concerts du Groupe Le Vivier, ainsi que quelques «Nouveautés en bref». Sharon Kanach offre un compte rendu du recueil de textes Ivan Wyschnegradsky. Libération du son:écrits 19161979, tandis qu'Éric Legendre parcourt les pages des trois premiers numéros de la revue TACET.

Pour conclure, signalons au passage la parution de l'ouvrage La création musicale au Québec qui propose un tour d'horizon de la création musicale depuis 50 ans à travers l'analyse de 21 œuvres de 16 compositeurs, de Serge Garant à Nicole Lizée ${ }^{6}$. Bon nombre des chapitres prennent comme point
5. Fausto Romitelli (2003), Professor Bad Trip, ensemble Ictus, dir. GeorgesÉlie Octors, Cyprès CYP5620.

6. Jonathan Goldman (dir.) (2014), La création musicale au Québec, Montréal, Presses de l'Université de Montréal. Voir : <www.pum. umontreal.ca/catalogue/creationmusicale-au-quebec-la> (consulté le 15 septembre 2014). 
7. Voir: <http://cmcquebec.ca/ materielpedagogique> (consulté le 15 septembre 2014) de départ des articles parus dans Circuit dans la rubrique Cahier d'analyse (Jean Lesage, dir.), mais adaptés dans une optique pédagogique. Le site Internet qui accompagne le livre, hébergé par le Centre de musique canadienne, offre l'écoute en streaming des œuvres étudiées, ainsi que la plupart des partitions?

Bonne lecture!

Montréal, septembre 2014

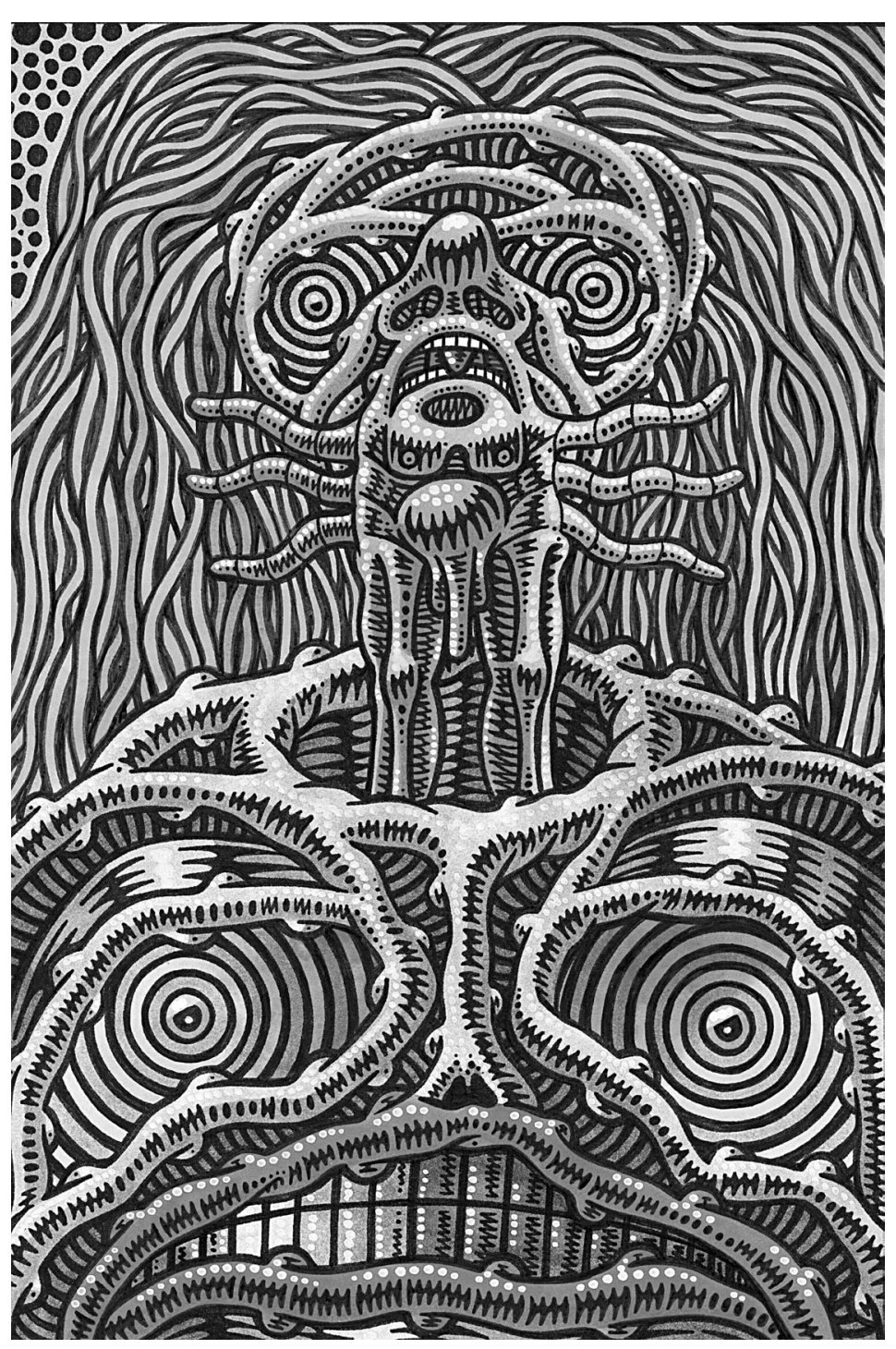

Gianluca Lerici, Mutante, 1997. Encre de Chine et aquarelle sur papier, $20 \times 30 \mathrm{~cm}$. 